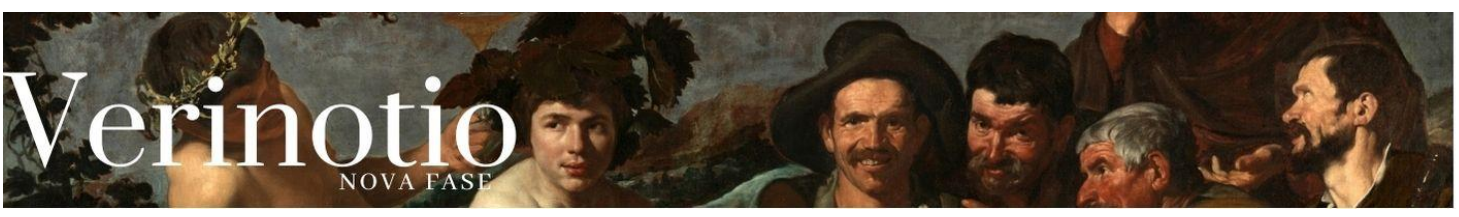

\title{
Ontologia do ser social: considerações sobre o valor e o dever-ser em Lukács*
}

\section{Ana Selva Albinati*}

\begin{abstract}
Resumo: O texto apresenta a análise de Lukács acerca do valor e do dever-ser no interior da ontologia do ser social. Identificando a gênese dessas duas categorias puramente sociais no processo de trabalho, o autor afirma essa esfera como protoforma das demais formas mais complexas da práxis social, cujas distinções podem ser compreendidas segundo "uma relação de identidade de identidade e nãoidentidade". Uma vez esclarecida essa relação, Lukács dialoga com a tradição filosófica sobre questões tais como a objetividade/subjetividade do valor, a autenticidade histórico-social dos valores, o caráter imanente do dever-ser, entre outras.
\end{abstract}

Palavras-chave: Lukács; valor; dever-ser; trabalho; ética.

\begin{abstract}
The text presents the analysis of Lukács about the value and the ought-to-be within the ontology of social being. Identifying the genesis of these two purely social categories in the work process, the author affirms this sphere as a protoform of the others more complex forms of social práxis, whose distinctions can be understood in "a relationship of identity identity and nonidentity". Once this relationship is clarified, Lukács dialogues with the philosophical tradition on issues such as the objectivity/subjectivity of value, the historicalsocial authenticity of values, the imanente character of the ought-to-be, among others.
\end{abstract}

Keywords: Lukács; value; ought-to-be; work; ethics.

O esforço lukácsiano de maturidade é consagrado a uma elucidação das categorias sociais em suas interrelações, esforço que nos deixou uma extensa e ainda inconclusa apresentação da efetiva relação entre os fenômenos abrangidos na esfera das formações ideais, incluindo as instâncias normativas, que se orientam a partir de valores, e a esfera da produção e reprodução da vida, como instância ontologicamente prioritária da vida humano-social. Na sua análise sobre o valor, Lukács trata de dilemas tais como a universalidade ou a relatividade dos valores, a objetividade ou subjetividade dos valores, o problema da contraditoriedade entre os valores, a partir de um tratamento desse complexo de questões, ordenado sobre a perspectiva marxiana de compreensão da existência social.

Ele se interroga sobre a gênese das categorias do valor e do dever-ser,

\footnotetext{
* Texto com reformulações a partir do originalmente publicado em VAISMAN, E.; VEDDA, M. (Orgs). Lukács: Estética e Ontologia. São Paulo: Alameda, 2014, pp.123-137.

" Doutora pela UFMG e professora do departamento de filosofia da Pontifícia Universidade Católica de Minas Gerais.
} 
identificando-a no ato inaugural da existência social, que é o trabalho. Da análise do trabalho, em seu sentido mais geral, como produtor de valores de uso, Lukács extrai uma série de esclarecimentos acerca dos atributos propriamente sociais, aquelas categorias que se fazem presentes apenas quando da passagem do ser orgânico ao ser social. Recusando as formulações filosóficas que atribuem um dever-ser aos seres naturais na forma de uma teleologia de origem transcendente, o autor encaminha sua reflexão no sentido de demonstrar a gênese do dever-ser e do valor - duas categorias estreitamente relacionadas - no processo de trabalho, quando, ao lidar com a objetividade natural, o homem projeta e realiza uma objetividade para-nós, moldando o que se deseja a partir de um ser em si que porta determinadas potencialidades.

O valor se refere ao que é desejável enquanto ser-para-nós. É apenas no ser social, na interrelação entre a consciência que coloca um pôr teleológico, e a natureza minimamente conhecida em seus nexos causais, que surge o ser-para-nós. $O$ valor, nesse sentido, está presente no produto como idealidade que pode ser objetivada através de comportamentos pautados por um dever-ser. Esclarecendo essas duas categorias que fazem parte do mesmo complexo, diz Lukács:

Indissoluvelmente ligado ao problema do dever-ser enquanto categoria do ser social está o problema do valor. Pois, assim como o dever-ser enquanto fator determinante da práxis subjetiva no processo de trabalho só pode cumprir esse papel específico determinante porque o que se pretende é valioso para o homem, então o valor não poderia tornar-se realidade em tal processo se não estiver em condições de colocar no homem que trabalha o dever-ser de sua realização como princípio orientador da práxis (LUKÁCS, 2013, p. 106).

O valor influi na posição do fim desejado, está em relação estreita com o por teleológico e com o julgamento que se faz acerca do produto alcançado (se é provido ou desprovido de tal valor). Já o dever-ser atua como regulador da práxis, orientandoa rumo à obtenção daquele valor.

O valor é, portanto, uma categoria social, desconhecida nas esferas naturais, uma vez que o valor está relacionado ao por teleológico, atividade subjetiva por excelência. As formulações filosóficas que afirmam o valor em si, presente nos seres naturais como uma propriedade objetiva, compartilham da ideia de uma criação transcendente que sustente tal objetividade. Aliada a essa perspectiva, está a suposição de uma teleologia da natureza, na qual os seres naturais, criados por uma inteligência transcendente, possuem um valor em si e assumem papéis no interior de uma teleologia natural. A análise de Lukács busca, ao recusar tal fundamentação filosófica, uma proposição que responda também ao extremo inverso dessa postulação, qual seja, às posições 
filosóficas que retiram da objetividade qualquer elemento passível de valoração, respondendo à pergunta pela origem do valor através do reconhecimento da mesma em uma operação subjetiva tão somente. A atividade de valoração seria assim uma operação dos sujeitos frente a uma objetividade neutra. É valioso o que o sujeito delibera como portando valor, o que pode ser extremamente variado a ponto de se tornar uma questão indefinível. A esse respeito, Lukács reitera que, se o valor não se extrai de forma natural da objetividade, é na transitividade entre subjetividade e objetividade que ele se estabelece, de forma que também a posição subjetivista acerca da origem do valor é desqualificada pelo autor: "O valor de uso não é um simples resultante de atos subjetivos, valorativos, mas, ao contrário, estes se limitam a tornar consciente a utilidade objetiva do valor de uso; é a constituição objetiva do valor de uso que demonstra a correção ou incorreção deles e não o inverso" (LUKÁCS, 2013, p. 108).

Para tal constituição do valor de uso, o conhecimento da objetividade, de sua causalidade natural, é de fundamental importância, de tal forma que os polos da objetividade enquanto possibilidade natural posta e da subjetividade que coloca um télos como produto a partir dessa possibilidade, estão intimamente conectados na gênese do valor. Essa relação entre subjetividade e objetividade se mantém, nos termos da relação teleologia-causalidade, desde a sua expressão na esfera do trabalho enquanto produtor de valor de uso, até as suas formas mais espiritualizadas, mais puramente sociais. Lukács elucida a origem do valor e do dever-ser a partir da atividade do trabalho, detendo-se na análise do valor de uso, e toma o trabalho como modelo para se pensar todas as outras formas de valor e de dever-ser implicadas nas atividades mais espirituais da vida humana. No caso do trabalho, o critério do valor está muito imediatamente colado ao que é útil: o valor de uso diz exatamente essa condição de algo que serve à alguma finalidade. No entanto, mesmo nesse caso, a categoria da utilidade não deriva imediatamente da natureza, não é um atributo natural, mas, ao contrário, só pode ser apreendida como realidade na relação com os indivíduos em situação histórico-social determinada, uma vez que o sentido do que seja útil acompanha as transformações sociais. Como Marx nos esclarece em $O$ Capital, os valores de uso são históricos, o que torna impertinente pensar em termos de valor ao se tratar meramente do ser natural.

Em relação ao dever-ser, também é a partir do trabalho que Lukács identifica a sua gênese: "A essência ontológica do dever-ser no trabalho dirige-se, certamente, ao 
sujeito que trabalha, e determina não apenas seu comportamento no trabalho, mas também seu comportamento em relação a si mesmo enquanto sujeito do processo de trabalho" (LUKÁCS, 2013, p. 104).

O dever-ser atua como mediação no processo de trabalho, ajustando o comportamento ao fim almejado e informado pelo valor. Mas o ponto mais interessante dessa observação de Lukács é que isso não se refere apenas aos procedimentos técnicos implicados na relação com as objetividades no sentido de torná-las "paranós", mas também, e fundamentalmente, ao comportamento do indivíduo em relação a si mesmo. O domínio de suas faculdades, o autocontrole sobre suas forças essenciais e a disciplina frente ao processo de trabalho para atender ao fim almejado são fatores fundamentais no processo de vida social, de interação dos indivíduos entre si, de tal forma que Lukács afirmará a origem da liberdade como decisão entre alternativas que se encontra primariamente na atividade do trabalho, como decorrente desse domínio das faculdades e transformação da natureza interior dos indivíduos, como elementos que de fato atualizam a decisão, a tornam efetiva enquanto ação no mundo.

Em suma, a análise do trabalho realizada por Lukács acompanha e desenvolve a formulação marxiana de que os homens transformam a natureza externa e a sua natureza interna, situando nesse momento singular do processo de socialização, a origem das categorias mais elevadas e espirituais que definem o ser social. Como afirma o autor, "o dever-ser do trabalho desperta e promove certas qualidades dos homens que mais tarde serão de grande importância para formas da práxis mais desenvolvidas; é suficiente recordar o domínio sobre os afetos" (LUKÁCS, 2013, pp. 104-5).

Já a partir dessas poucas referências, podemos compreender o alcance de suas considerações quando ao final do capítulo sobre o trabalho, o autor afirma a rica significação do trabalho no processo de hominização do homem, mas também no de humanização do homem, pois como ele mesmo reconhece, trata-se de reconhecer muito mais coisas no processo de trabalho do que tradicionalmente se quer admitir:

Independentemente da consciência que o executor do trabalho tenha, ele, nesse processo, produz a si mesmo como membro do gênero humano e, desse modo, o próprio gênero humano. Poder-se inclusive dizer, de fato, que o caminho do autocontrole, o conjunto das lutas que leva da determinidade natural dos instintos ao autodomínio consciente, é o único caminho real para chegar à liberdade humana real (LUKÁCS, 2013, p. 155).

Ao se debruçar sobre a análise das categorias implicadas no complexo do 
trabalho, a intenção de Lukács é reposicionar a discussão sobre o dever-ser e os valores em sua efetiva relação com a vida humana em sua totalidade. É uma resposta à filosofia idealista que relega a expressão material da vida a um estado natural, a uma face de menor importância na definição do que seja o ser humano. Lukács, ao afirmar, de acordo com a análise marxiana, a ineliminável mediação que existe entre a esfera material e as expressões ideais em seus níveis mais sofisticados, intenta demonstrar os equívocos das filosofias que autonomizam essas duas esferas em um ou em outro sentido, confundindo a questão da prioridade ontológica com a dimensão axiológica. Em sua longa explanação dedicada a essa questão, o autor não deixa de advertir que a consideração do trabalho enquanto modelo para toda práxis social não encobre as profundas diferenças entre essas práxis, a saber, "que entre o modelo e suas sucessivas e mais complexas variantes há uma relação de identidade de identidade e não identidade" (LUKÁCS, 2013, p. 104).

Sua intenção era, como se sabe, a constituição de uma ética materialista, que pudesse responder aos impasses relativos a uma hipostasiação dos valores, tidos como eternos e universais, por um lado, e uma posição subjetivista que reduzisse o estatuto dos valores à mera escolha subjetiva, por outro. Tinha uma profunda consciência da dificuldade de se tratar dessa questão ao largo dos encaminhamentos relativos à elucidação das categorias que constituem o ser social. Por isso, não raras vezes, encontramos passagens nas quais Lukács se refere à intenção de uma melhor abordagem dessas questões no que seria o exame da ética, o que nos foi deixado inconcluso. De toda forma, os lineamentos deixados por ele nos permitem uma compreensão dos fundamentos de sua reflexão ética ou, ao menos, a limpeza do terreno sobre o qual ele pretendia realizar sua reflexão. Nesse sentido, a tematização da gênese das categorias fundamentais das expressões normativas da vida social nos oferece um entendimento que nos permite atravessar o conjunto de equívocos que se encontra a respeito de categorias tais como a liberdade, o valor, o dever-ser.

O que Lukács realiza é o ancoramento ontológico da vida espiritual, realizada a partir de determinados valores que determinam as escolhas individuais relativos aos pores teleológicos secundários. Em outras palavras, ele esclarece os vínculos dessa instância - ainda que reconhecendo e destacando a imensa complexidade que diferencia as ações nesse âmbito mais estritamente social das relações humanas - com a sua gênese no trabalho e com a forma determinada da reprodução da vida social. $A$ consideração do trabalho como protoforma das relações sociais se coloca em vista da 
emergência que se tem no processo de trabalho da configuração adequada entre causalidade e pôr teleológico:

\begin{abstract}
Teleologia e causalidade não são, como até agora aparecia nas análises gnosiológicas ou lógicas, princípios mutuamente excludentes no desdobramento do processo, do ser-aí e do ser-assim das coisas, mas ao contrário, princípios mutuamente heterogêneos, que, no entanto, apesar da sua contraditoriedade, somente em comum, numa coexistência dinâmica indissociável, podem constituir o fundamento ontológico de determinados complexos dinâmicos, complexos que só no campo do ser social são ontologicamente possíveis, cuja ação nessa coexistência dinâmica constitui a característica principal desse grau do ser (LUKÁCS, 2013, p. 89).
\end{abstract}

Todas as práticas sociais, por mais complexas que sejam, se assentam sobre essa relação entre causalidade e teleologia. A noção abstrata de liberdade cede lugar aqui ao entendimento da liberdade enquanto decisão subjetiva individual frente a essa relação, no sentido de procurar fazer valer determinadas posições teleológicas futuras. Assim, a respeito da liberdade, nos diz Lukács:

\begin{abstract}
A liberdade obtida no trabalho originário era, por sua natureza, primitiva, limitada; isso não altera o fato de que também a liberdade mais alta e espiritualizada deve ser conquistada com os mesmos métodos com que se conquistou aquela do trabalho mais primitivo, e que o seu resultado, não importa o grau de consciência, tenha, em última análise, o mesmo conteúdo: o domínio do indivíduo genérico sobre a sua própria singularidade particular, puramente natural. Nesse sentido, acreditamos que o trabalho possa ser realmente entendido como modelo de toda liberdade (LUKÁCS, 2013, p. 156).
\end{abstract}

A gênese da liberdade se encontra na relação consciente que se estabelece entre o por teleológico - em sua conjunção com o valor -, e as condições objetivas nas quais a ação se dará, o que se traduzirá por uma práxis orientada por um dever-ser. Nas formas mais espiritualizadas das relações humanas, essa premissa ontológica permanece, ou seja, o valor se realiza no agir que, por sua vez, pressupõe uma objetividade social dada. O valor, para se realizar, necessita de uma substancialidade social, sem a qual seria apenas uma ideia vazia de sentido, sem vínculo com a realidade.

Em consonância com o texto marxiano, Lukács enfatiza o caráter histórico da substância social, da qual se derivam as expressões ideais. Isso equivale a dizer do caráter social do valor e do dever-ser. Estes não exibem uma racionalidade transcendental, nem são frutos de uma argumentação racional, a não ser que se compreenda esta última como assentada sobre a substancialidade social concreta. $O$ conteúdo do dever-ser se refere a uma dada configuração social, que para se reproduzir, coloca determinadas finalidades no que se refere ao comportamento dos indivíduos sociais. Lukács contrapõe-se assim às filosofias idealistas que, 
negligenciando a relação entre as instâncias da vida social, autonomizam a esfera da moralidade e pretendem enfatizar o polo da consciência sobre o da necessidade. Dessa forma, a moral é tida abstratamente como um universo autônomo e superior às atividades relacionadas mais diretamente à reprodução material da vida social.

Sempre que as filosofias idealistas pretendem ver aí um dualismo, elas colocam em confronto, em geral, as funções da consciência humana (aparentemente) apenas espirituais, inteiramente separadas (aparentemente) da realidade material, com o mundo do ser meramente material. Não surpreende, então, que o terreno da atividade propriamente dita do homem ou seja, o seu metabolismo com a natureza, do qual ele provém, mas que domina cada vez mais mediante a sua práxis e, em particular, mediante o seu trabalho, perca sempre mais valor e que a única atividade considerada autenticamente humana caia ontologicamente do céu pronta e acabada, sendo representada como "supratemporal", "atemporal", como mundo do dever-ser contraposto ao ser (LUKÁCS, 2013, pp. 61-2).

O pensamento idealista seria incapaz de estabelecer as relações ontológicas reais, na medida em que inverte a ordem determinativa, priorizando e autonomizando a instância das expressões ideais. Sustenta dessa forma artificiosa uma esfera do dever-ser auto-gestada, posta abstratamente sobre a realidade das relações sociais, e incapaz de se perceber enquanto momento de inteligibilidade dessa mesma realidade. O ponto culminante dessa absolutização da razão se encontra na filosofia moral de Kant, na qual:

o dever-ser se apresenta - subjetiva e objetivamente - como algo separado
das alternativas concretas dos homens; à luz de uma tal absolutização da
ratio moral, essas alternativas aparecem como meras encarnações adequadas
ou inadequadas de preceitos absolutos, permanentes, portanto,
transcendentes ao homem (LUKÁCS, 2013, p. 101).

Lukács escapa do rigorismo kantiano que afirma o dever de forma tautológica como a ação por respeito à lei oriunda de uma razão prática pura. O dever-ser em Lukács encontra o seu esclarecimento em vista do por teleológico, informado pelo valor. Essas categorias - valor, por teleológico, dever-ser - se encontram assentadas em uma substancialidade social da qual retiram sua razão de ser. A diferença fundamental entre o exercício dessas categorias na esfera da moral, em relação à esfera da reprodução material da vida, diz respeito ao nível de complexidade e de indeterminação que se acentua nas esferas superiores da vida social. Enquanto no trabalho as tomadas de posição alternativa são mais simples e unívocas, "nas tomadas de posição morais perante certas consequências da economia sobre a vida parece dominar um antagonismo de valores" (LUKÁCS, 2013, p. 120). Em outras palavras, a complexidade das tomadas de posição no campo propriamente dito da moralidade está em que se trata da relação não com objetos e sua causalidade, mas da relação 
com sujeitos e situações existenciais cuja causalidade é sempre mais imprecisa e cujo resultado é imprevisível. É a esfera dos pores teleológicos secundários que envolvem indivíduos diversos em situações particulares diversas e que, nessa medida, costuma dar-se em meio a valores antagônicos que expressam a particularidade dos sujeitos envolvidos.

Essas alternativas antagônicas parecem indicar uma falta de fundamentação objetiva para os valores, questão que levou Max Weber a cair em uma concepção trágico-relativista, segundo a qual o pluralismo conflitual de valores é o fundamento da práxis humana, portanto, um fundamento decisionista em última instância, que sucumbiria ao irracionalismo. Observa Lukács que se pode identificar, no tratamento reservado à problemática dos valores, basicamente duas posições filosóficas, que seriam a do relativismo histórico e a do dogmatismo lógico-sistemático. Enquanto a primeira reduz os valores à uma expressão casuística, ligados de maneira linear à uma situação histórica determinada, a segunda tende a homogeneizá-los num sistema formal, que culmina na sua "desistoricização". Segundo sua análise, o tertium datur para essa antinomia se encontra na concepção de "substancialidade" do processo histórico, que "se conserva em essência, mas de modo processual, transformando-se no processo, renovando-se, participando do processo" (LUKÁCS, 2012, p. 413). Nessa concepção, os valores perdem a sua pretensão de eternidade, mas, por outro lado, se justificam, em virtude de, autenticamente, corresponderem ao curso do processo social. Em relação ao aparente pluralismo de valores, observa Lukács:

\footnotetext{
Isso, no entanto, é apenas uma aparência. Com efeito, atrás dele não se oculta a própria realidade, mas, por um lado, a permanência na imediatidade com a qual se mostram os fenômenos e, por outro, um sistema hiperracionalizado, logicizado, hierárquico, dos valores. Esses extremos igualmente falsos produzem, quando são postos em marcha de maneira autônoma, ou um empirismo puramente relativista ou uma construção racionalista não aplicável adequadamente à realidade; na medida em que um é relacionado com o outro, nasce a aparência de que a razão moral é impotente diante da realidade (LUKÁCS, 2013, p. 121).
}

Aqui, tocamos em um aspecto fundamental da análise lukácsiana. Primeiramente, torna-se compreensível todo o seu esforço em recuperar o método de investigação marxiano, recuperar o vínculo entre essência e fenômeno para, a partir daí, pavimentar o caminho que permite atravessar as dicotomias que se erguem na história da filosofia, aqui, especificamente, em torno da questão da escolha moral. A passagem acima é exemplar desse procedimento: o antagonismo de valores é compreendido por Lukács não enquanto uma realidade inapreensível, de fundo irracionalista, e sim como uma 
expressão fenomênica dessa realidade que se explica pela própria pluralidade e antagonismo concretamente existente no ser social. Para não se cair no empirismo relativista, nem no seu extremo que seria uma hiperracionalização dos valores considerados subsistentes por si mesmos, é preciso compreender a autenticidade de determinados valores a partir da base social que lhes dá origem: "A fonte autêntica dessa gênese é, muito mais, a transformação ininterrupta da estrutura do próprio ser social, e é dessa transformação que emergem diretamente os pores que realizam o valor" (LUKÁCS, 2013, p. 122).

O reconhecimento da gênese social dos valores permite a compreensão da contradição entre valores surgidos da mesma realidade social. Essa contradição objetiva está relacionada aos antagonismos da reprodução social como um todo, na qual se encontram separados e, por vezes, contrapostos os interesses dos indivíduos em sua particularidade e em sua constituição como generidade para si. Lukács se refere nesse ponto à própria lógica da reprodução da ordem econômica que inclui não só um antagonismo entre "a essência objetiva de seu processo e suas respectivas formas fenomênicas na vida humana, mas faz do antagonismo um dos fundamentos ontológicos do próprio desenvolvimento em seu conjunto" (LUKÁCS, 2013, p. 121).

Isso leva, no plano da ideação dos valores, a dois fenômenos aparentemente contraditórios: em primeiro lugar, uma aparente contraposição entre a ordem moral e a ordem econômica, aspecto já examinado por Marx nos Manuscritos econômicofilosóficos. Nesse momento, Marx nos aponta que, de maneira aparentemente paradoxal, os valores normativos a um só tempo correspondem e se contrapõem à ordem econômica, uma vez que os valores contrapostos se exercem nos limites da própria ordem econômica.

Lukács chama atenção para o fato de que, no que se refere à essência do processo, temos uma coercitividade que Marx já tematizava dizendo de uma objetividade econômica que "arrasta os indivíduos sob pena de ruína". Essa objetividade, por si só, coloca questões de ordem moral para os indivíduos em suas decisões cotidianas. Enquanto no plano da essência, a contradição se instala na forma do antagonismo social, de forma que a evolução humana se dê sob a marca de uma contraditoriedade essencial, essa fonte de conflitos se amplifica no plano fenomênico, assumindo formas variadas que tocam a vida cotidiana de modo desigual, através de estranhamentos diversos, e que recebe dos indivíduos as mais diversas respostas. 
Uma vez retida a significação adequada do remetimento que Marx faz da esfera dos valores não econômicos à base produtiva da existência social, Lukács não recai na interpretação reducionista que trata as formas de consciência como meros epifenômenos da infraestrutura. Ao contrário, o surgimento de valores sociais diversos e contraditórios entre si atesta a complexidade da constituição das esferas que compõem o conjunto das formações ideais, e que expressam parcelas do conteúdo social e das relações sociais postas por um dado modo de produção. Em sua expressão fenomênica, tem-se a aparência de que os valores não portam uma necessidade em si, - que leva à suposição de que cabe aos indivíduos decidirem em meio a uma disputa caótica de valores. Porém, diferentemente disso, Lukács identifica que as contradições entre as instâncias reguladoras das relações sociais e a base econômica não significam uma falta de correspondência, que permitiria a consideração autônoma dos valores, tal como se verifica na postura idealista, mas, ao contrário, essa relativa autonomia constitui-se como um elemento necessário na reprodução da ordem social.

Lukács desenvolve ainda essa questão ao retomar a relação singular-particularuniversal no que se refere aos antagonismos presentes nas possibilidades da escolha moral. Aqui, tem-se a compreensão do autor acerca da ética enquanto ultrapassamento da particularidade rumo à universalidade do gênero. Reconhecendo a objetividade da contradição social entre indivíduo e gênero, o autor aponta, no entanto, o papel da subjetividade em relação à sua condição particular, que se coloca entre a fixação imediatista na particularidade ou o agir consciente com vistas à superação do aprisionamento na particularidade, o que significa a passagem do gênero em si ao gênero para si.

Um outro aspecto merece ser apontado aqui: na mesma passagem acima citada, ao se referir à postura dogmático-logicizante e à postura relativista acerca do pluralismo de valores, Lukács se vale da seguinte expressão: "Quando se os relaciona entre si, apresentam a aparência de uma impotência da razão moral frente à realidade." O que é curioso é que ele se exprime usando uma expressão célebre de Marx: "A moral é a impotência posta em ação" (MARX; ENGELS, 1974, p. 307), porém, com um sentido diferente. Enquanto para Marx, a questão se refere à situação paradoxal da moral, aos limites da moral frente à existência social, em Lukács a impotência não se refere propriamente à moral em si, mas tal impotência seria uma aparência a ser desfeita atendo-se ao entendimento ontológico do fenômeno da moralidade. 
Se atentarmos a essa distinção entre os dois autores, perceberemos que se trata de duas perspectivas que, embora exibam uma série de consonâncias, nesse ponto apresentam diferenças significativas. Marx constata a situação paradoxal da moral, na medida em que esta "toda vez que luta contra um vício, perde" (MARX; ENGELS, 1974, p. 307), se deparando com a irresolução via moral (e política) para os impasses da sociedade capitalista, apontando, consequentemente, para uma resolução social. Já Lukács, ainda que não negligencie a vinculação entre a objetividade social e as possibilidades individuais, assegura o lugar da ética no interior das atividades humanas como fundamentalmente a possibilidade da transcendência da particularidade rumo à construção consciente do gênero para si. O caráter da individualidade é enfatizado em Lukács:

Embora seja, no fundo, óbvia a permanência do estranhamento como fenômeno social, e que, por isso mesmo, em última análise ele só possa ser superado por vias sociais, para a condução da vida de uma pessoa, assume sempre o lugar de um problema central quanto à realização ou ao fracasso do desenvolvimento pleno da personalidade, quanto à superação ou à persistência do estranhamento na própria existência individual (LUKÁCS, 2010, p. 244).

Nesse ponto, o encaminhamento do autor em direção à constituição de uma ética constitui um voo-solo em relação a Marx, na medida em que este trabalha o tema da moralidade objetiva, enquanto expressão ideal que dota de inteligibilidade as relações concretas entre os indivíduos, mas não desenvolve os elementos de uma ética. 0 encaminhamento de Lukács, nesse sentido, se apresenta como uma caminhada original na qual a relação objetivação-alienação-estranhamento é trabalhada de forma diferente da qual se encontra nos textos de Marx. Importa sublinhar que, no âmbito em que se registra a reflexão de Lukács, nos traços mais gerais do ser social, ele reflete a partir da condição do trabalho como produção de valor de uso, o que autoriza a distinção entre as categorias Entäusserung e Entfremdung, ao passo que Marx aproxima essas categorias na medida em que reflete sobre o trabalho sob o capital. Embora não seja esse o espaço adequado para tratar dessa questão complexa, a forma peculiar como Lukács compreende a alienação (Entäusserung), como exteriorização que retorna modificando o sujeito, parece apontar para uma tematização que abre a possibilidade de uma ética, enquanto o que encontramos em Marx é uma elucidação mais objetiva da relação entre alienação e estranhamento, mediada pela condição específica da compra e venda generalizada da mercadoria força de trabalho.

Uma outra questão significativa quando se pensa as considerações de Lukács 
acerca dos valores seria em relação à autenticidade e à transformação destes. Vimos como, a respeito do valor de uso, o autor registra que o critério do valor está associado à sua utilidade. $\mathrm{O}$ valor não pode obter-se imediatamente das coisas naturais, mas só na medida em que se torna útil para a vida humana. Isso vale tanto para os valores de uso quanto para os valores mais espirituais. Quanto a esse aspecto, poderíamos nos colocar o seguinte problema: como dizer de uma gênese social dos valores, sem colar essa gênese ao imediatismo de uma prática social marcada pela fragmentação, pela oposição da vida civil, pela exigência pragmática da qual brotaria o sentido do útil, e portanto, do valor? Como vincular o útil, que se refere ao que é (no interior de uma existência social dada) a um dever-ser (que pressupõe uma normatividade) através da definição do que é "valor" (sendo que este se gesta na relação subjetividadeobjetividade, portanto, em uma efetividade dada)? Em suma, em que Lukács se distingue de uma perspectiva pragmatista?

Podemos dizer que Lukács se distingue da postura pragmatista basicamente ao resguardar e tematizar a diferença entre aparência e essência e ao distinguir, a partir daí, a diferença entre o processo objetivo da evolução humano-social e sua apreciação axiológica. No que se refere aos valores morais, o deslocamento do sentido do útil está vinculado à pretendida superação da generidade em si em nome da generidade para si, o que transcende a mera utilidade imediata dos valores. Ou seja, os valores podem entrar em conflito em vista de interesses mais ou menos imediatos, aqueles que dizem respeito à esfera fenomênica mais vulnerável ao imediatismo da vida cotidiana, e aqueles que dizem respeito à transcendência da particularidade rumo à generidade humana. O útil, e portanto, a questão da objetividade do valor, se confirma pela afirmação da posição teleológica, que se traduz em atos de alienação, que em sua totalidade, definem o caráter de um indivíduo. Mas longe de ser um mero voluntarismo, ou de um apelo piedoso, o autor chama a atenção para o fato de que a posição teleológica diz respeito às objetividades em questão, senão redundaria em quimera. Essa posição teleológica, que na esfera do trabalho, diz respeito à causalidade natural, nas esferas mais espirituais, diz respeito à essência genérica do homem, em última instância. Donde o útil se eleva a uma dimensão que escapa ao pragmatismo.

De fato, há o reconhecimento da utilidade como categoria central no estabelecimento do valor, ou seja, o valor se refere àquilo que é desejável, o que guarda relação estreita com o que é útil, seja no nível mais restrito das situações 
individuais, seja no âmbito mais alargado da reprodução social. No entanto, isso não significa dizer da admissão da utilidade retirada acriticamente das condições empíricas da existência humano-social. Em outras palavras, o remetimento ao solo ontológico do qual brotam os valores não significa a capitulação empirista às condições da reprodução social. Nesse sentido, o que é útil transcende a empiria e se coloca no patamar mais elevado do que sejam as verdadeiras necessidades humanas, e mais que isso, às verdadeiras possibilidades humanas, que dariam passagem da generidade em si à generidade para si. Com isso, tocamos em um último aspecto da análise de Lukács acerca dos valores que precisa ser ressaltado nesse momento: o caráter de sua análise é objetivo-ontológico, o que significa dizer, como ele mesmo o faz em várias passagens, que remeter a esfera dos valores à sua base econômica não significa em momento algum um procedimento axiológico. Trata-se, tão somente, de identificar a gênese e a relação entre as instâncias do ser social, o que não significa rebaixar o significado dos valores na condução da vida humana. Ao contrário, a identificação de tal gênese não retira o sentido do elemento moral e sim o torna mais compreensível. Sobre o elemento valorativo, ele observa: "Se, no entanto, esse momento é absolutizado de maneira improcedente, cai-se numa concepção idealista do processo histórico-social; se simplesmente ele é negado, incorre-se naquela carência de conceitos que se encontra indefectivelmente presente na praticista Realpolitik (LUKÁCS, 2013, p. 154).

No que se refere à esfera das relações interpessoais, tem-se que os traços individuais dos homens singulares imprimem nuances significativas do ponto de vista moral e social. A deliberação individual a partir da eleição de um valor frente a outro torna-se um elemento essencial na reprodução ou transformação de uma substancialidade social. $O$ apreço à dimensão ética transparece ao longo da obra do autor, para o qual "todas as valorações que alcançam validade nessas decisões subjetivas estão ancoradas na objetividade social dos valores, na importância destes para o desenvolvimento objetivo do gênero humano" (LUKÁCS, 2013, p. 154).

\section{Referências bibliográficas}

LUKÁCS, G. Para uma ontologia do ser social. v. I. São Paulo: Boitempo, 2012.

LUKÁCS, G. Para uma ontologia do ser social. v. II. São Paulo: Boitempo, 2013.

LUKÁCS, G. Prolegômenos para uma ontologia do ser social. São Paulo: Boitempo, 2010.

MARX, Karl; ENGELS, Friedrich. A sagrada família. 2. ed. Lisboa: Presença; Martins 
Fontes, 1974.

Como citar:

ALBINATI, Ana Selva. Ontologia do ser social: considerações sobre o valor e o deverser em Lukács. Verinotio, Rio das Ostras, v. 27, n. 1, pp. 338-351, jan./jun 2021. 